\title{
Article
}

\section{Determination of spreading and flow behavior of brazing fillers}

\author{
Thomas Uhligi,*, Benjamin Sattler ${ }^{1}$, Guntram Wagner ${ }^{1}$ and Sebastian Weis ${ }^{2}$ \\ 1 Chemnitz University of Technology, Germany \\ Benjamin Sattler, M.Sc.; benjamin.sattler@mb.tu-chemnitz.de; \\ Prof. Guntram Wagner; guntram.wagner@mb.tu-chemnitz.de; \\ 2 University of Applied Sciences Zwickau, Germany \\ Prof. Sebastian Weis; sebastian.weis@fh-zwickau.de; \\ * Correspondence: Thomas Uhlig, Ph.D.; thomas.uhlig@mb.tu-chemnitz.de
}

Received: 08.08.2019; Accepted: 28.09.2019

\begin{abstract}
The development of new brazing fillers requires knowledge about their properties in comparison to well established fillers. Therefore, the determination of the spreading and flow behavior is necessary. By now, different measuring techniques are combined in order to reach a comprehensive understanding of the mechanisms. Especially in case of flux brazing, conventional measuring techniques cannot be used. Due to the industrial demand of application-related experiments, the intended setup should be simple and easily to arrange. This paper deals with the development of a new procedure to determine the spreading and flow behavior of brazing fillers employing flux. The experimental setup, which consists of a commercially available induction heater, equipped with a temperature controller, is mounted inside a gas and vacuum tight chamber. A CCD camera system is used to record the spreading and flow behavior on surfaces as well as inside narrow gaps. The results of experiments using different fillers and base materials are presented. The measurements of the spreading area and the flow velocity under defined conditions allow a quantitative evaluation of the properties of the fillers. Thus, the comparison of different fillers among each other is possible.
\end{abstract}

Keywords: brazing; spreading; flow

\section{Introduction}

To evaluate the processing properties of brazing fillers, some conventional methods are well established. One of the most common properties is the wetting angle of the brazing filler on a distinct base material. The Young-Dupré' equation describes fundamental relations between contact angle, the surface energies and the interfacial tensions [1]. In comparison to this basic calculation, which assumes idealized conditions, further equations by Wenzel or Cassie are more useful in practice. But also these equations partly represent what actually happens [2,3]. The spreading and flow of brazing fillers is a sophisticated process that cannot be described easily due to the variety of mutual parameters, as already stated by Prabhu and Shibata [4,5]. Only a few methods to examine the properties of the fillers are based on dynamic tests. For example the wetting method in v-grooves after Yost et al. [6] or tests on capillary gaps by Hall et al. [7]. These tests and similar methods are limited by means of the test conditions. For most practical applications, the results are not transferrable. Additionally there is a demand from the industry to carry out fast and easy measurements. Other important subjects are repeatability, comparability of results, time need for analysis and the capturing of flow and spreading phenomena in real time. In contrast to previously established methods, the procedure may be carried out using fluxes.

\section{Materials and Methods}

The basic measuring principle is recording the spreading and flow behavior during testing. A simple CCD-camera captures single images of the base material surface in time intervals of $100 \mathrm{~ms}$. For the implementation of this procedure, a special test bed was designed and built, which allows different process atmospheres (Fig. 1a). Therefore, the samples are fixed in the center of a gas and vacuum tight chamber. The radiation in the visible light spectrum, emitted by the sample due to its high temperature, was recorded. The image sequences were used for a quantitative evaluation of the spreading and flow behavior as described in detail later. The samples were heated up by an induction coil with a maximum output power of $15 \mathrm{~kW}$. The temperature measurement as well as the automatic control of the power output were carried out by 
thermocouples and an adapted controller. Thus, the heating rate and the brazing temperature could be set easily. The arrangement of base material and brazing filler was placed on a height adjustable carrier made of graphite. Thereby it was possible to change the samples position within the focus of the camera and the induction field. During induction heating, the cylindrical shape of the samples offers the advantage of a uniform temperature distribution. The samples can be manufactured easily, allowing a simple use of the test in industrial practice. In all employed tests, the sample arrangements were placed horizontally in order to annihilate gravity effects. Two types of sample geometries were used for the investigations (Fig. 1b).

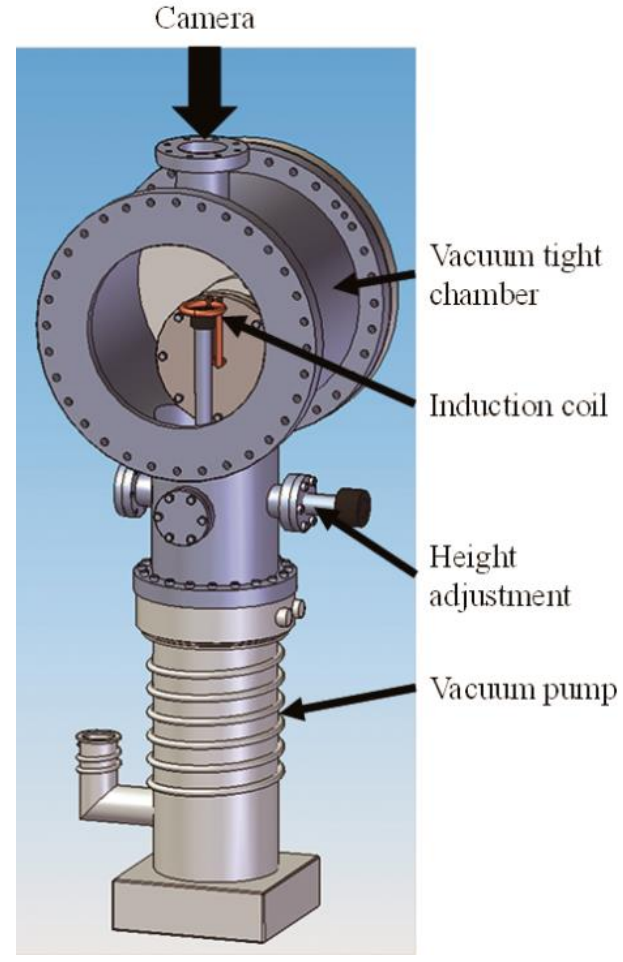

(a)

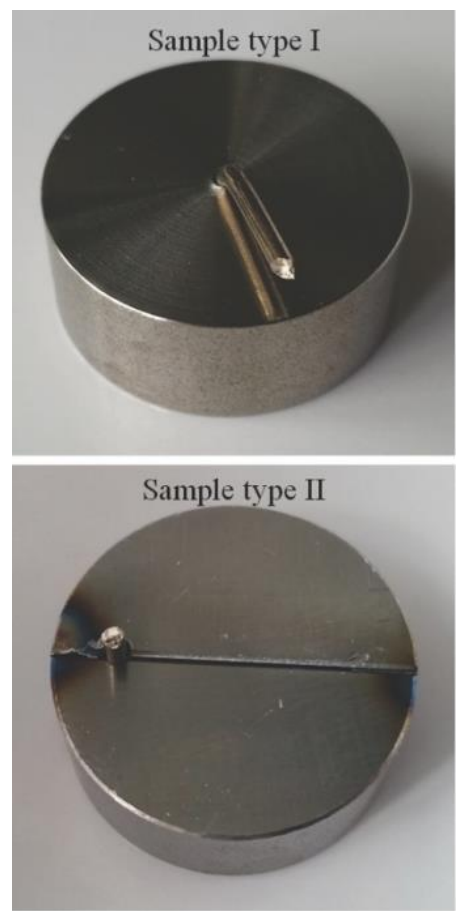

(b)

Fig. 1. a) Main components of the test bed; b) geometries of samples: "type I" for investigations on a free surface, "type II" for investigations inside a gap

Sample "type I" provides a drilled hole in the center of the base material. The brazing filler in form of a kinked piece of wire is fixed in a well-defined position. This arrangement was used to examine the flow characteristics on surfaces. After melting the filler, a sufficient wetting area is provided for observation. The other geometry "type II" was used for testing the flow behavior in gaps. The gaps were fabricated by cutting the cylindrical samples in half and welding the parts together with defined spacers in between. To validate the repeatability and differentiability of the results, the measuring principle was tested on $\mathrm{Ag} / \mathrm{Cu}-$ and $\mathrm{Cu}-$ -based fillers (table I.) Some of the fillers are not listed in AWS A5.8 and ISO 17.672. Therefore, the classifications after ISO 3677 are used.

Table I. Investigated brazing fillers

\begin{tabular}{cccc}
\hline $\begin{array}{c}\text { brazing filler } \\
\text { ISO 3677 }\end{array}$ & $\begin{array}{c}\text { brazing filler } \\
\text { ISO 17672 }\end{array}$ & $\begin{array}{c}\text { brazing filler } \\
\text { AWS A5.8 }\end{array}$ & $\begin{array}{c}\text { min. brazing } \\
\text { temperature }\left[{ }^{\circ} \mathrm{C}\right]\end{array}$ \\
\hline B-Ag72Cu-780 & AG 401 & BAg-8 & 780 \\
B-Ag60CuSn-600/730 & AG 402 & BAg-18 & 720 \\
B-Ag35CuZnMnSnSi-680/700 & not listed & not listed & 700 \\
B-Cu60Zn(Si)(Mn)-870/900 & CU 303 & not listed & 900 \\
\hline
\end{tabular}

\section{Results}

The first step during setting up the test bed was the determination of the substantial influencing parameters. The effect of the temperature, which was considered to be one of the most important factors, was determined by several preliminary tests. A certain amount of brazing filler was applied on mild steel in combination with flux. Then the arrangements were heated up until the liquidus temperature of the brazing filler as well as several temperatures above the liquidus. In figure 2, a comparison of images during the tests 
at different temperatures and the corresponding samples after the tests are shown. It appears that temperatures above the liquidus do not lead to an essential difference in spreading, even when the temperature exceeds $110 \%$ of liquidus.
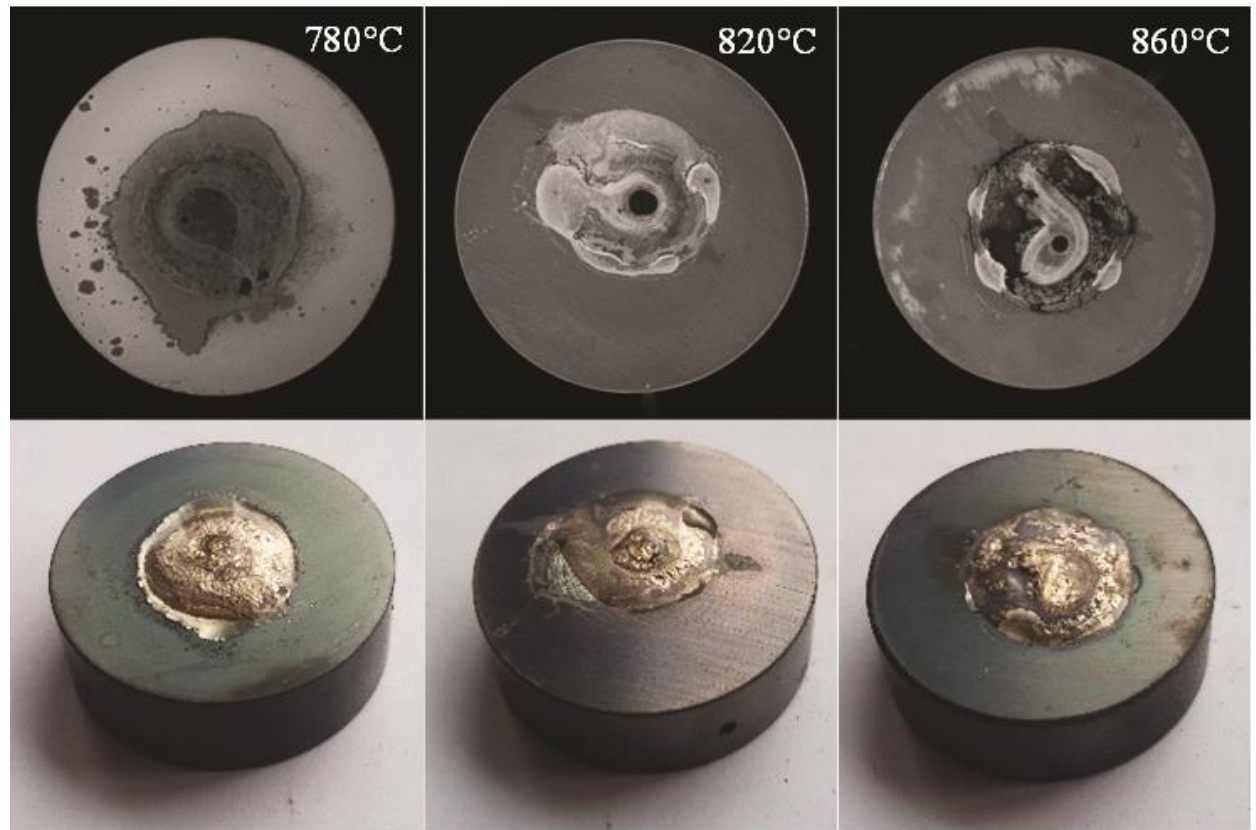

Fig. 2. Influence of temperature on wetting of B-Ag72Cu-780 on mild steel

Another factor is the surface treatment of the base material. This includes cleaning conditions as well as structures caused during the manufacturing of the samples. To show this effect, base material samples with grinding grooves were used. Figure 3 points out, how the spreading and flow behavior of the brazing filler are influenced by different surface conditions. The orientation of the grooves was tilted in steps of $45^{\circ}$ in relation to the centerline of the applied filler wire. It is visible, that the direction of the grooves leads to preferred paths of flow. To eliminate this detrimental influence, the samples used for further experiments were finished by precision turning. This leads to nearly radially symmetric structures as can be seen in figure 3.

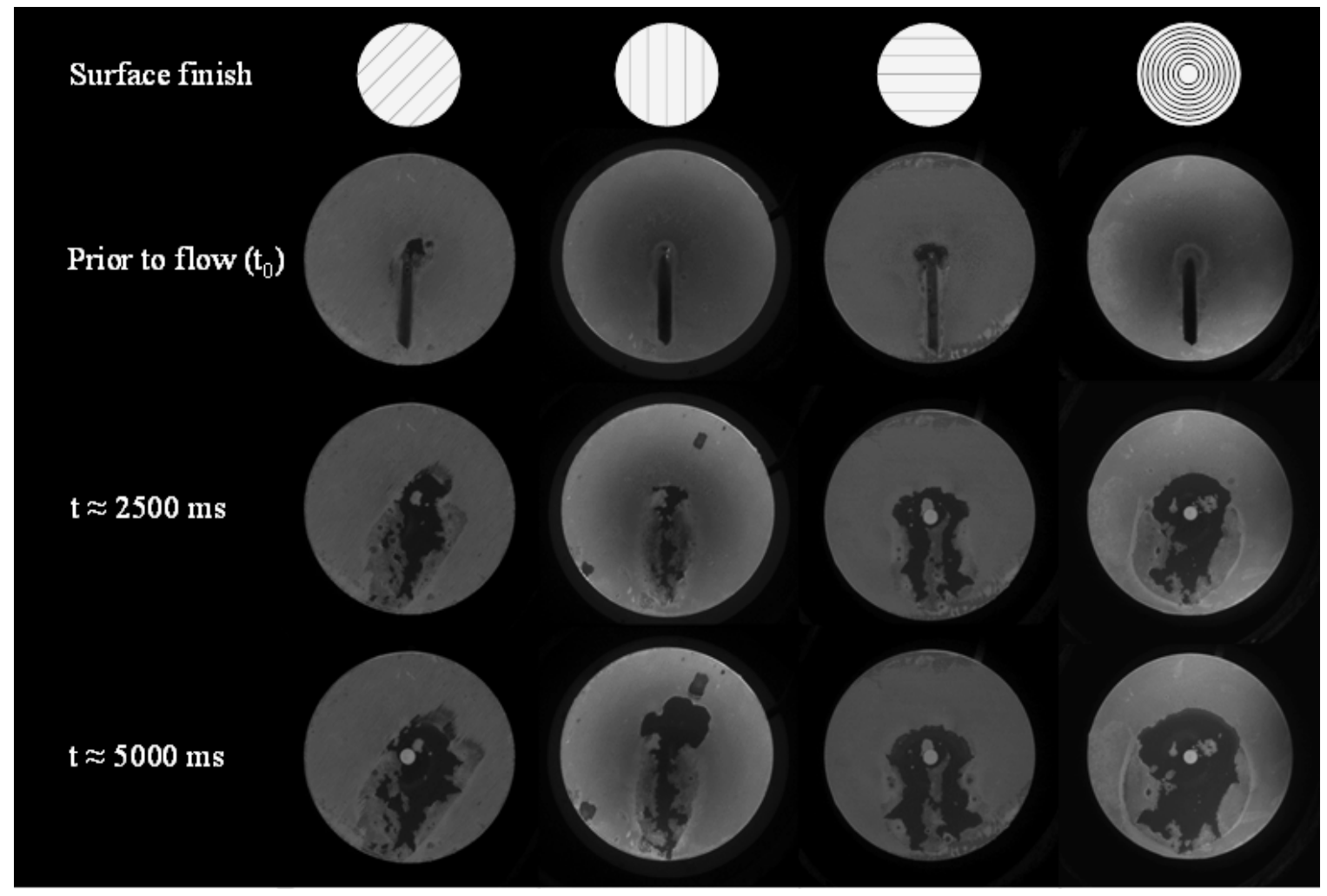

Fig. 3. Influence of the surface finish on wetting of B-Ag72Cu-780 on mild steel 
The interpretation of experimental data and quantification of the results will be explained using "type I" samples. A constant amount of brazing filler in form of wire was placed on the radially symmetric turned substrate surface. The width of the spreading area was determined to quantify the results. To involve the dynamics of the spreading process, a parameter of time is necessary. A distinct period of time, which can be chosen according to the spreading kinetics, started when the brazing filler began to melt. Afterwards the widths of the spreading areas were measured. In the performed investigations a period of $5 \mathrm{~s}$ was set. An example of the spreading process and the measurement of the width of the spreading area is shown in figure 4 .

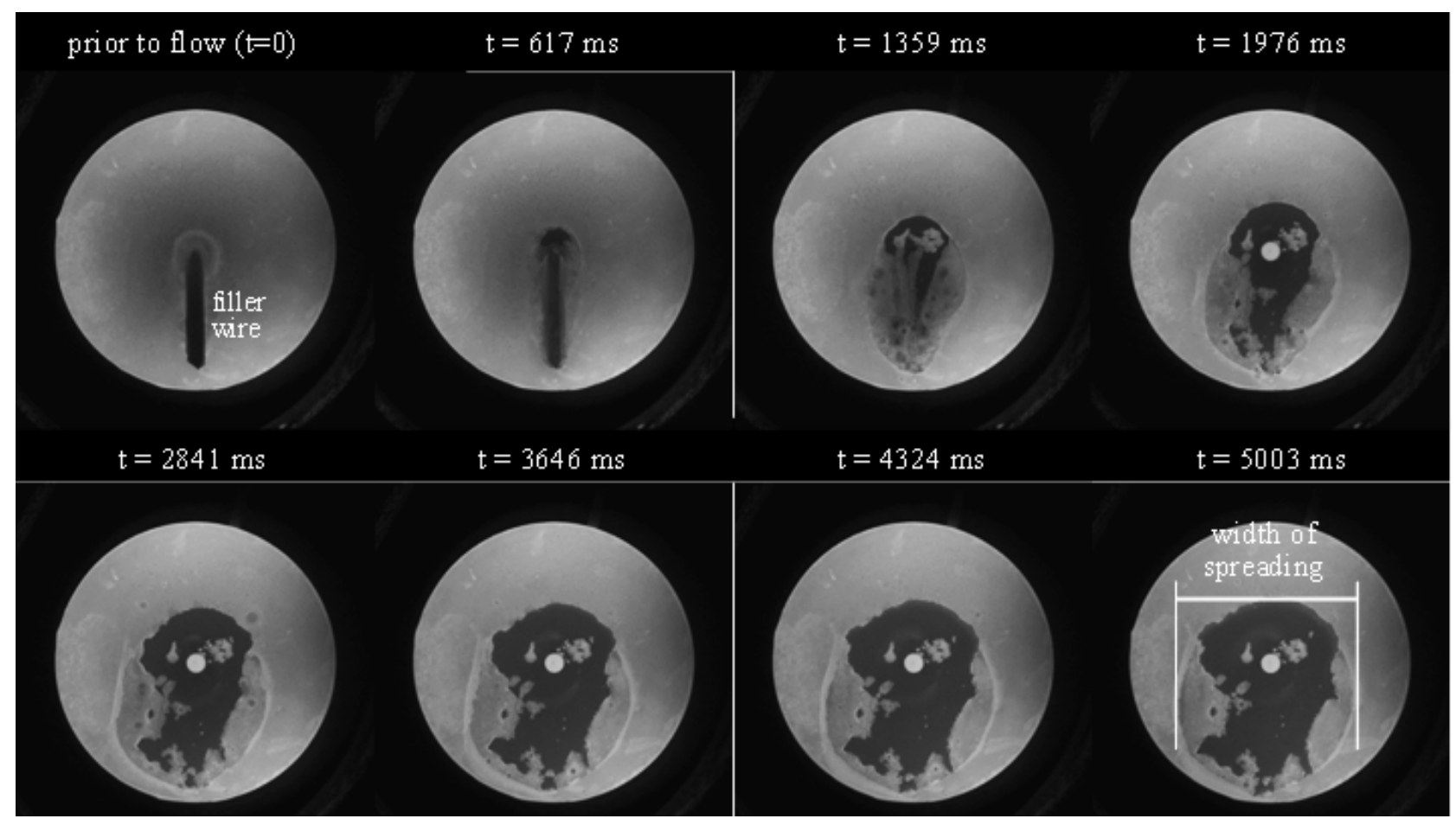

Fig. 4. Measurement of the spreading width using sample "type I"

The test procedure was evaluated with the two fillers B-Ag72Cu-780 (BAg-8) and B-Ag35CuZnMnSnSi $-680 / 700$ on four different base materials using flux. The determined values of spreading width are shown in figure 5. It can be seen, that the wetted areas of the two fillers do not differ significantly on mild steel substrates. In contrast to that, on stainless steel and copper, B-Ag35CuZnMnSnSi-680/700 spreads about twice as wide as B-Ag72Cu-780. An opposite effect occurs on brass CuZn37.

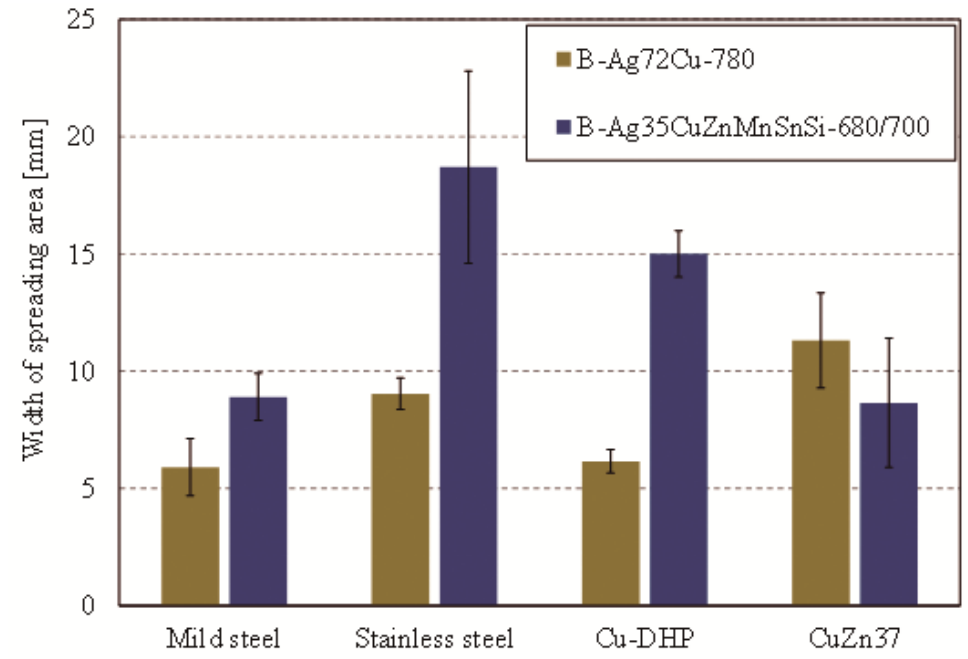

Fig. 5. Measured width of spreading areas of two brazing fillers on four different base materials

The experimental setup for the investigation of the flow behavior in gaps using sample "type II" is presented in figure 6. In this case, the flow velocity of the liquid brazing filler inside the gap is of interest. The values were determined using single frames of the CCD camera. First tests were carried out using gap 
widths of $50 \mu \mathrm{m}$ and $100 \mu \mathrm{m}$. A width of $150 \mu \mathrm{m}$ leads to accurately evaluable images. Due to the reduction of the flow velocity inside the wider gap, the results can be distinguished more easily. Apart from that, the flow front is better detectable. At first, the possible flow distance respectively length of the gap is measured. After that, considering the fact, that the capture time of every single frame is known, the duration of the flow process can be determined. An average velocity can be calculated using that information. In figure6, an example sequence is shown. The arrows indicate the different locations of the flow front inside the gap during the test.

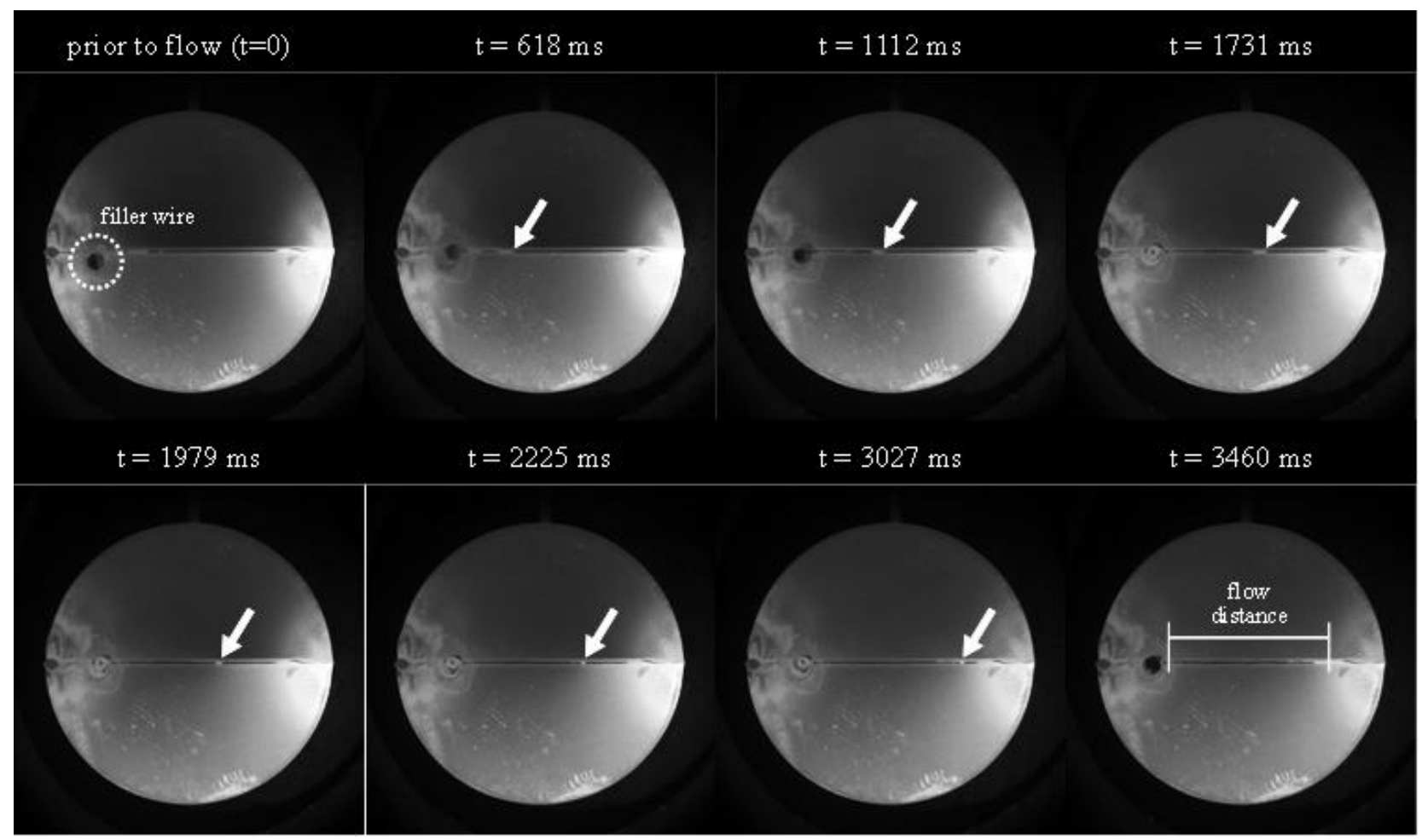

Fig. 6. Measurement of the flow velocity in gaps using sample "type II"

The experiments were carried out using four brazing fillers on two different base materials. The calculated values of the flow velocities range between $1 \mathrm{~mm} / \mathrm{s}$ and $15 \mathrm{~mm} / \mathrm{s}$. The results are summarized in figure 7. A standard deviation of about $20 \%$ of the mean value occurs in each sample series. The brazing fillers B-Ag72Cu-780 (BAg-8), B-Ag35CuZnMnSnSi-680/700 and B-Cu60Zn(Si)(Mn)-870/900 exhibit significantly higher flow velocities than B-Ag60CuSn-600/730 (BAg-18).

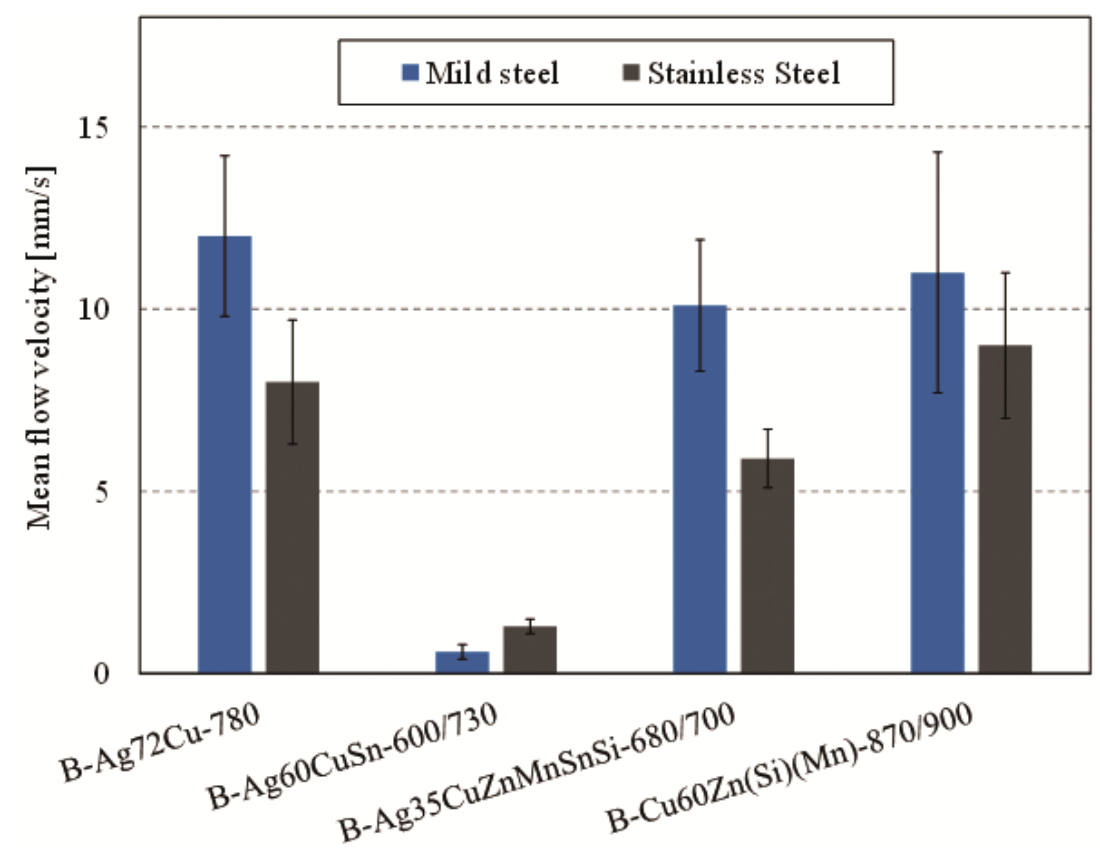

Fig. 7. Calculated mean flow velocities of four brazing fillers on two different base materials 


\section{Discussion}

During preliminary tests, the influence of the test temperature, which was considered to be one of the most important factors, was determined. The effect of overheating the filler above its liquidus was negligible in the investigated temperature range. These results could be explained by two effects. On the one hand, the viscosity of the melt may not change significantly due to the overheating. On the other hand, the surface tension may have a stronger effect than the viscosity. The obtained results represent an advantage of the test procedure, because the results of the measurements do not change when a slight overheating takes place. The effect of the surface treatment of the base material was also considered. Grinding groves led to preferred paths of flow, which would influence the measured values of the spreading width. To eliminate this detrimental influence, the samples were precision turned, leading to nearly radially symmetric structures. Hence, the quantification of the results is not influenced by the positioning of the brazing filler and the base material to each other.

During the spreading experiments, a time period of $5 \mathrm{~s}$ was set. On the one hand, $5 \mathrm{~s}$ of spreading time allow a proper distinction of the quantitative results with regard to the use of different fillers. On the other hand, it is short enough to avoid the wetting of the whole sample surface. The results of the spreading experiments show, that B-Ag35CuZnMnSnSi-680/700 spreads about twice as wide as B-Ag72Cu-780 on stainless steel and copper. An opposite effect occurs on brass CuZn37. This effect may be explained by the contents of alloying elements with a high vapor pressure (20 wt. $\% \mathrm{Zn}$ and $10 \mathrm{wt} . \% \mathrm{Mn})$ in the filler B-Ag35CuZnMnSnSi-680/700. On steel and copper substrates the wetting kinetics seem to improved thereby. On brass, which contains $37 \mathrm{wt}$.\% of zinc itself, these elements seem to be detrimental. In order to clarify this effect, further investigations are necessary.

The results of the flow experiments in gaps point out, that the brazing fillers B-Ag72Cu-780 (BAg-8), B-Ag35CuZnMnSnSi-680/700 and B-Cu60Zn(Si)(Mn)-870/900 exhibit significantly higher flow velocities than B-Ag60CuSn-600/730 (BAg-18). This fact can be explained by the higher melting range of the non-eutectic filler B-Ag60CuSn-600/730 which leads to a higher viscosity of the melt. Reference data on flow velocities tend to noticeably higher values, see Yost et al. [6] for example. The lower values in this investigation are probably caused by the flow resistance that the molten flux generates when it is displaced by the liquid brazing filler.

\section{Conclusions}

In the present study, a new procedure was investigated, to characterize the spreading and flow behavior of brazing fillers using an in situ test considering fluxes. One of the main objectives was using a simple, but practice oriented experimental setup. Furthermore, the test should be expeditious and easy to establish. The properties of different brazing fillers can be compared to each other regarding the width of the spreading areas and the flow velocities inside gaps. The evaluation generates quantitative results on these properties for different combinations of brazing fillers and base materials. There is a scatter in the results, which is caused by the dynamics of the process, but the mean values show clear tendencies, which allow a distinction of the different properties of the fillers. Further research will investigate the feasibility of using fillers in form of pastes for the developed procedure.

Acknowledgments: Part of the research was carried out within the scope of the project \# 18705 BR funded by the Bundesministerium für Wirtschaft und Energie (BMWi) via the Arbeitsgemeinschaft industrieller Forschungsvereinigungen "Otto von Guericke" e.V. The authors thank the BMWi for financing this project.

Conflicts of Interest: The authors declare no conflict of interest.

\section{References}

[1] Zaremba P., Hart- und Hochtemperaturlöten, DVS-Verlag, Düsseldorf, Germany, 1988.

[2] Villanueva W., Boettinger W. J., Warren J. A., Amberg G., Effect of phase change and solute diffusion on spreading on a dissolving substrate, Acta Materialia, 2009, Vol. 57(20), 6022-6036. [CrossRef]

[3] Yost F.G., The triple line in reactive wetting, Scripta Materialia, 1988, Vol. 38(8), 1225-1228. DOI: 10.1016/S13596462(98)00030-X

[4] Kumar G., Prabhu K.N., Review of non-reactive and reactive wetting of liquids on surfaces, Advances in Colloid and Interface Science, 2007, Vol. 133(2), 61-89. [CorssRef] 
[5] Shibata H., Jiang X., Valdez M., Cramb A. W., The Contact Angle between Liquid Iron and a Single-Crystal Magnesium Oxide Substrate at 1873 K, Metallurgical and Materials Transactions B, 2004, Vol. 35(1), 179-181. [CrossRef]

[6] Yost F.G., Rye R.R., Mann J.A. Jr., Solder wetting kinetics in narrow V grooves, Acta Materialia, 1997, Vol. 45(12), 5337-5345. [CorssRef]

[7] Hall A.C., Hosking F. M., Reece M., Visual observations of liquid filler metal flow within braze gap, Science and Technology of Welding and Joining, 2004, Vol. 9(2), 95-102. [CrossRef]

(C) 2019 by the authors. Submitted for possible open access publication under the terms and conditions of the Creative Commons Attribution (CC BY) license (http://creativecommons.org/licenses/by/4.0/). 